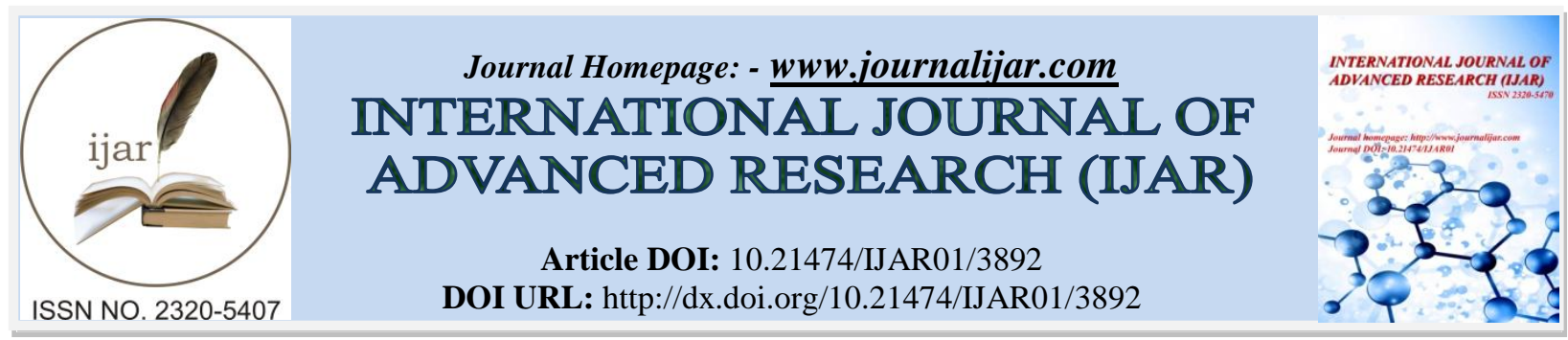

RESEARCH ARTICLE

\title{
MORPHOLOGICAL PERFORMANCE AND SURVIVAL RATE OF FRAGMENTED CARPET ANEMONE (Stichodactyla gigantea) IN FLOATING NET CAGES.
}

\author{
Muhammad Marzuki", Muhammad Junaidi, Baiq Hilda and Astriana Muhammad Ridwan. \\ Aquaculture Study Program of Mataram University.
}

\section{Manuscript Info}

Manuscript History

Received: 13 February 2017

Final Accepted: 11 March 2017

Published: April 2017

Key words:-

Fragmentation, Morphologic

performance, Stichodactyla gigantea

\begin{abstract}
Fragmentation is asexual reproductive system carpet anemone (Stichodactyla gigantea) by way of division of the body so as to form a new individual from a single individual so as to accelerate the process of reproduction. The study aims to determine the effect of fragmentation and fragmentation are best suited to the survival of the morphological and performance anemones carpet. Research using completely randomized design with 4 different treatment ie 1 to 2 individual treatments, treatment 2 to 3 individual, 3 to 4 individual treatment, and the treatment of 4 to 5 individual. Each treatment was repeated 4 replications and experimental units total 16 units trial. This study gets results with one treatment to get the best for the survival of $100 \%$, followed by treatment 2 that is $75 \%$, which is $75 \% 3$ treatment, and the treatment 4 is $25 \%$. As for the morphological performance in each individual Stichodactyla gigantea has almost the same response in all treatments cutting parts of the body so that there are no significant differences to express the fragmentation treatment.
\end{abstract}

Copy Right, IJAR, 2017,. All rights reserved.

\section{Introduction:-}

Carpet anemone (Stichodactyla gigantea) is part of the phylum Cnidaria, the main shaper of coral reef ecosystems. Anemone is one of the commodities waters that have ecological and economical value. Anemone symbiotic with reef fish like Amphiprion. Sea anemones and fish Amphiprion must live and grow together as if alone, growth and survival of one or both will be interrupted Uji (2014). Several types of sea anemones among others, Actinaria equima, Anemonia sulcata, Bunodactis verrocosa, Redianthus shame, is ornamental fish. Type of carpet anemones have the price is more expensive than other anemones, even been marketed to several countries such as Singapore, Europe, USA, and Canada as an ornamental anemones.

Anemone generally have ecological value can increase energy efficiency performance and be able to invite the presence of reef fish especially clownfish (Amphiprion) giving rise to the increasingly diverse trophic structure of the coral reef ecosystem. The presence of reef fish has a positive impact on the addition of organic matter derived from the stool. The anemone new population was able to increase the value and function of coral reef ecosystems. As a pioneer biota and improvement of emergency while waiting for the slow growth of the coral, which only reached 3-5 cm each year (Rifa'i, 2013). In addition, the seeds produced could be a new alternative to commercial marine farming to supply the market of ornamental fish or anemone in the country and abroad. Asexual reproduction technology is very possible developed in species other commercial interest of national and international markets.

Corresponding Author:- Muhammad Ridwan.

Address:- Aquaculture Study Program of Mataram University. 
Anticipating a decline in the population due to the high intensity of a sea anemone arrest in nature, seed propagation technology has been developed asexually by fragmentation technique to sea anemones. This technique is capable of producing seeds anemone quickly and a high survival rate when maintained in natural waters (Rifa'i, 2012). Asexual reproduction is better than sex because according to Purwati (2002) individual growth fragmentation results relatively quickly. Fragmentation does not require the number of individuals that much. In sexual reproduction, the relative amount of the parent in the population of the area is crucial habitat. Recruitment (addition of new individuals to habitat) through fragmentation does not require these requirements.

Seeing the potential, value, and functionality of its sea anemone, as well as the condition of current population that continues degraded, then the restocking efforts and cultivation should be done immediately. This effort requires anemone seeds in sufficient quantity and quality. Seeds required no longer possible to rely on natural seeds, but the seeds of conventional seeding results. Therefore, it is necessary to study the performance of morphological and life success rate of fragmentation anemones carpet.

\section{Material and Methods:-}

Research carried out for 30 days in January 2016 at the Center for Mariculture Sekotong, West Lombok district, West Nusa Tenggara province. The method used in the study is completely randomized design with four different treatments with treatment 1 to 2 individual, 2 to 3 individual, 3 to 4 individual, and 4 to 5 individual. A total of 16 experimental units with 4 replicates treatment.

\section{Implementation Research:-}

Preparation is done by preparing tools and materials used for the manufacture of insulation in floating net cages as a trial. Research bulkhead is made using wood and net with a size corresponding to the unit floating cage net a length of $30 \mathrm{~cm}$, width $30 \mathrm{~cm}$, and $50 \mathrm{~cm}$ high. Anemones carpet used is that size with an average diameter of $21.7 \mathrm{~cm}$. The anemone broodstock obtained from the waters of the West Sekotang. Anemone taken from floating cage net put into the jar containing sea water subsequently placed into a container basin of sea water and ice cubes with the aim of lowering the temperature to about $24-26^{\circ} \mathrm{C}$. Then mixed with antibiotics OTC (Oxytetraxyclin HCL) and left to soak for 30-60 seconds until the drug in the body absorb anemone.

The specimens were removed from the treatment above and placed on a piece of board abattoir. Fragmentation is done by using a scalpel. Pieces anemone re-incorporated into the container basin of antibiotics in order to avoid the emergence of pathogenic microorganisms. In addition, antibiotics can suppress the occurrence of infections due to cuts. This is consistent with the statement Murdiati (1997), ideally use of antibiotics to treat infectious diseases. Further cuts in the middle of the sea anemone's body using a surgical blade in accordance with the number of treatment.

The part that will do the fragmentation or cutting parts of the body, namely carpet anemone middle section of the body of $S$. gigantea. Before cutting the carpet anemone body soaked using antibiotics OTC (Oxytetraxyclin HCL) by soaking for three to five seconds in a bucket or jar. After anemones carpet was soaked then cropped in the midsection of the anemone carpet using a scalpel according to the amount of treatment that one piece will be a twopart, two-piece will be a three-part, three-piece will be four sections, and four pieces will be a five-part body carpet anemone. After cutting is completed, the body parts anemones carpet will be placed in the floating cage net has given bulkhead in a random way at each hole bulkhead cages.

\section{Observation and Data Analysis:-}

Survival level is calculated by using the formula Effendi (1979), SR = ((Nt / N0) $x 100 \%) . S R=$ Survival Rate; $\mathrm{Nt}=$ Total End; N0 = Number of Early.

The performance of morphological observations done visually with the aim to see the condition and health of the anemone is observed every day to see anemones cut. Observations attention active anemone tentacles, slime, anemones movement, color and anemones recovery. Ulfa (2009) argues anemone health condition indicated by the number of active tentacles, polyps color, shape, and filament mesenteri mucus or mucus production. 


\section{Result:-}

Based on the results of the performance of morphological study found that overall each treatment showed different morphological changes. In the treatment of F1 and F2 movement of the tentacles began to stabilize in the third day, the fourth day followed F3, F5 while for treatment with high cutting level, active tentacle movement on the fifth day. In all, there is a difference of treatment recovery time, F1 on day-10, F2 and F3 day 11, whereas F4 13th day. The results of the morphological appearance can be seen in Table 1 .

Table 1:- Morphological Performance.

\begin{tabular}{|c|c|c|c|c|c|c|c|c|c|c|c|c|c|c|c|}
\hline \multirow[t]{2}{*}{ Treatment } & \multirow[t]{2}{*}{ Morphological } & \multicolumn{14}{|c|}{ Days to - } \\
\hline & & 1 & 2 & 3 & 4 & 5 & 6 & 7 & 8 & 9 & 10 & 11 & 12 & 13 & 14 \\
\hline \multirow[t]{4}{*}{ F1 } & Tentacle & - & - & + & + & + & + & + & + & + & + & + & + & + & + \\
\hline & Mucus & - & + & + & + & + & + & + & + & + & 0 & 0 & 0 & 0 & 0 \\
\hline & Color & - & - & - & + & + & + & + & + & + & + & + & + & + & + \\
\hline & Recovery & - & - & - & - & - & - & - & - & - & + & + & + & + & + \\
\hline \multirow[t]{4}{*}{$\mathrm{F} 2$} & Tentacle & - & - & - & + & + & + & + & + & + & + & + & + & + & + \\
\hline & Mucus & + & + & + & + & + & + & + & + & + & + & 0 & 0 & 0 & 0 \\
\hline & Color & - & - & - & + & + & + & + & + & + & + & + & + & + & + \\
\hline & Recovery & - & - & - & - & - & - & - & - & - & - & + & + & + & + \\
\hline \multirow[t]{4}{*}{ F3 } & Tentacle & - & - & + & + & + & + & + & + & + & + & + & + & + & + \\
\hline & Mucus & + & + & + & + & + & + & + & + & + & + & 0 & 0 & 0 & 0 \\
\hline & Color & + & + & - & - & + & + & + & + & + & + & + & + & + & + \\
\hline & Recovery & - & - & - & - & - & - & - & - & - & - & + & + & + & + \\
\hline \multirow[t]{4}{*}{$\mathrm{F} 4$} & Tentacle & - & - & - & - & + & + & + & + & + & + & + & + & + & + \\
\hline & Mucus & + & + & + & + & + & + & + & + & + & + & + & + & + & + \\
\hline & Color & - & - & - & + & + & + & + & + & + & + & + & + & + & + \\
\hline & Recovery & - & - & - & - & - & - & - & - & - & - & - & - & + & + \\
\hline Inforamation: & $\begin{array}{l}\text { Tentacle }=+(\mathrm{I} \\
\text { Mucus } \\
\text { Color } \\
\text { Recovery }\end{array}$ & $\begin{array}{l}\text { e), } \\
=+ \\
=+ \\
=+\end{array}$ & $\begin{array}{l}(\mathrm{N} \\
(\mathrm{Th} \\
(\mathrm{No} \\
(\mathrm{Re}\end{array}$ & rma & $\begin{array}{l}\text { lovi } \\
\text { ), } \\
\text { r), - } \\
\text { r), }\end{array}$ & & & & & & $m$ & & & & \\
\hline
\end{tabular}

On a one-time treatment division and become two individual parts anemones carpet there are some changes in the behavior of different anemones in every performance of morphological observation. At the first measurement time, all individuals responded to the fragmentation by removing the mucus on the part being cut. Mucus in this treatment grow and disappear at every measurement as well as the perfect blend of growth is starting to look at the 11th day of measurement. From the mucus appears white bumps that will be part of the body to close wounds from cuts as presented in Figure 1. 


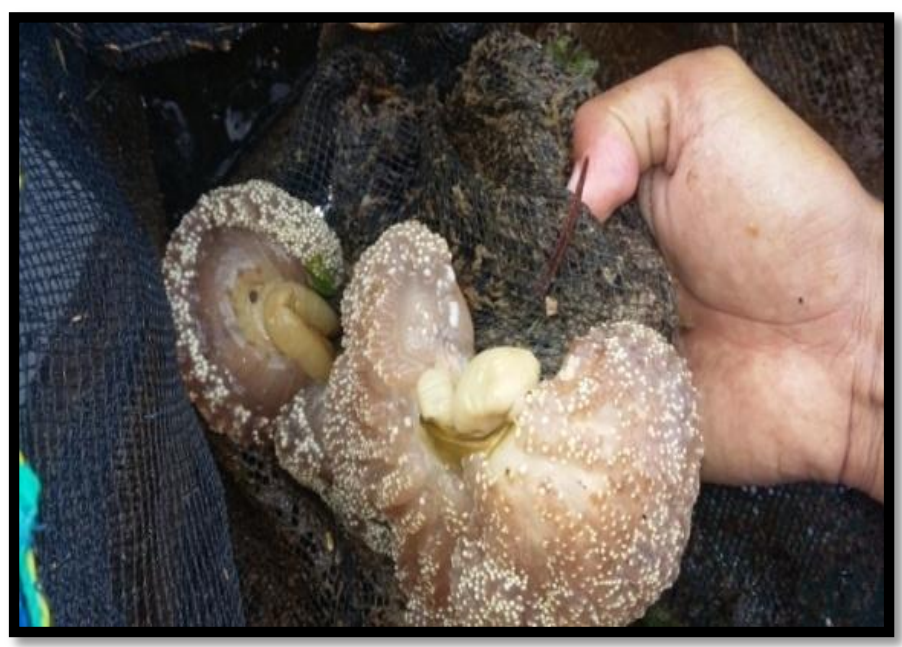

Figure 1:- The Protrusion White.

Living fragmentation highest success anemone that is $100 \%$ on F, F2 and F3 followed by $75 \%$, while the lowest fence at F4 That is $25 \%$. The high-level cutting living and the low success as seen in F4. Operates graph shown in Figure 2.

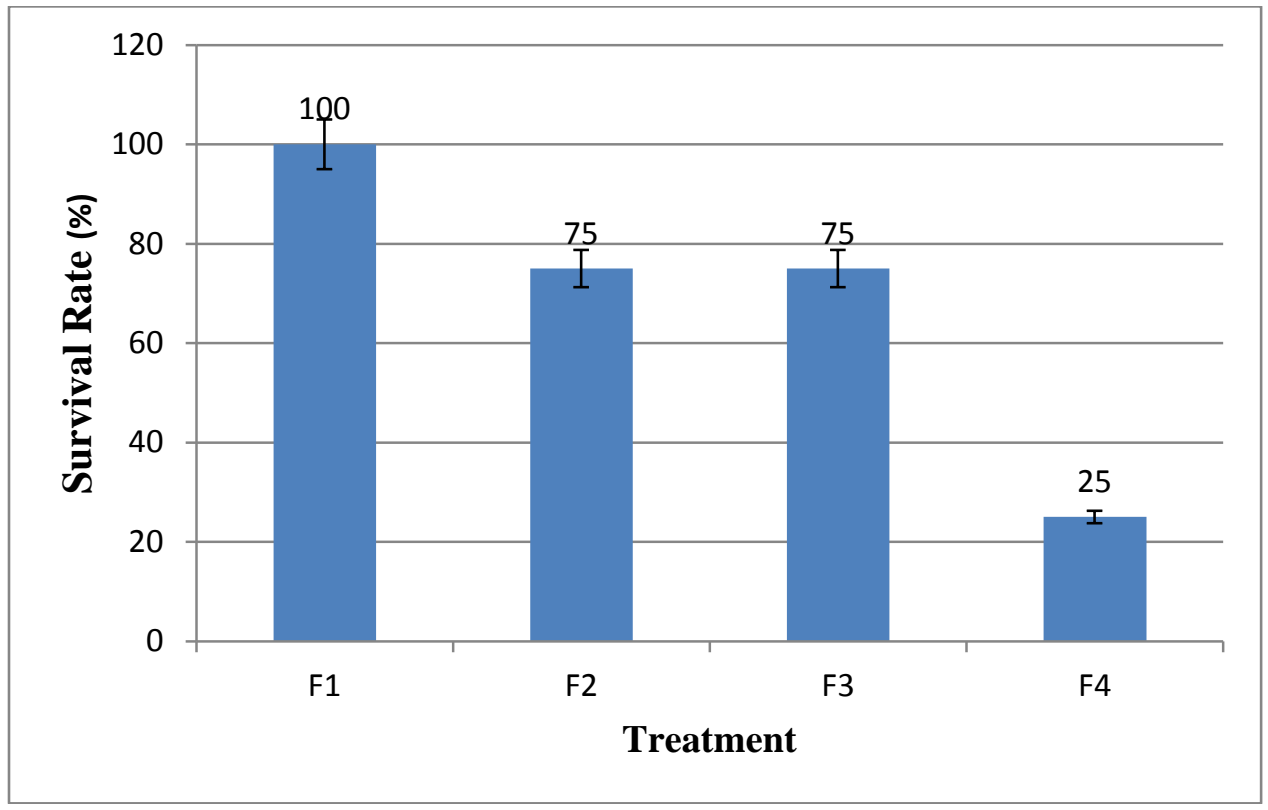

Figure 2:- Survival Rate (\%.)

Death anemones begin on a ninth day, marked by graying body parts anemone, tentacles destruction, and put out a foul smell. Graphically the mortality rate can be seen in Figure 4. 


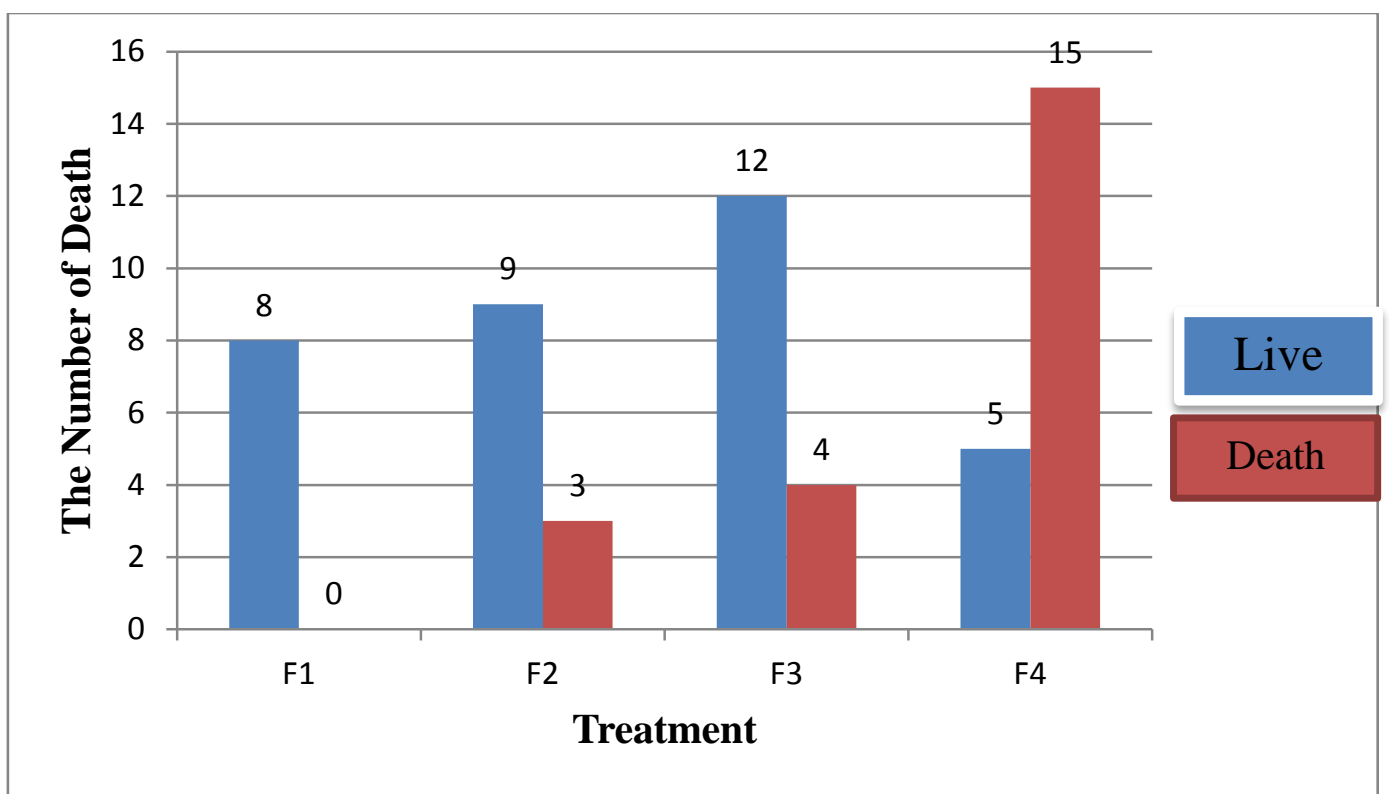

Figure 3:- Graph Death Stichodactyla gigantean.

Death Stichodactyla gigantea started on day nine, marked by graying body parts anemones, destruction of tentacles, and pull out the stench and continuously individuals on treatment two, the treatment of three, and the treatment of the four decay until the last day of the study as shown in Figure 5.

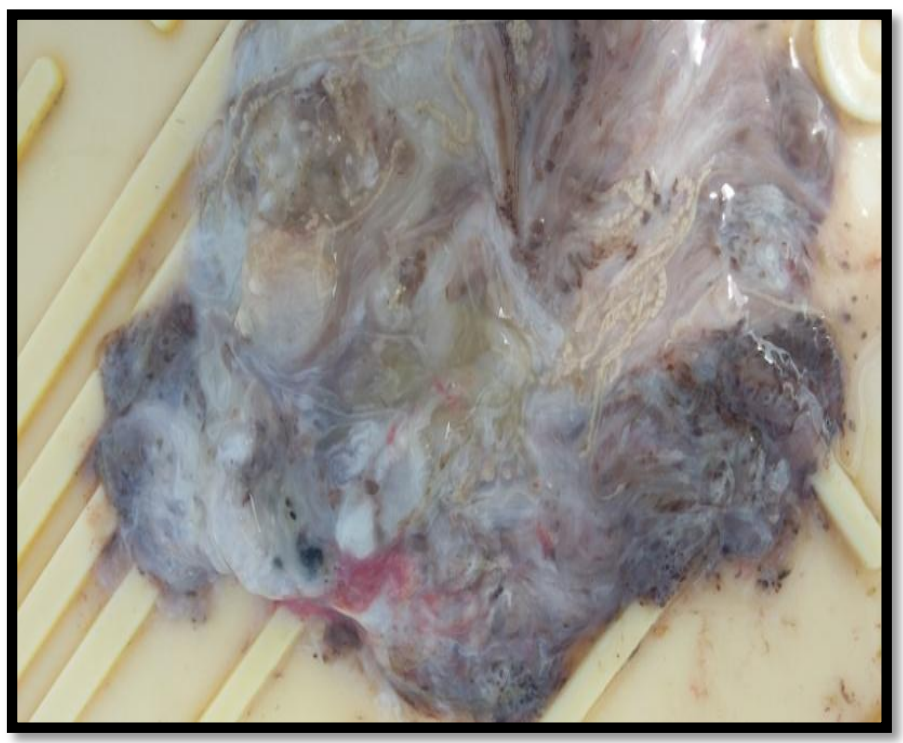

Figure 5:- Decomposing

\section{Discussion:-}

The visually morphological observation aimed to examine the health condition of the anemone. Ulfa (2009) argues that the health condition of the amount indicated anemone tentacles active, color polyps, mesenteric conditions filament, and mucus or mucus production. According to Sujangka (2014), morphological health anemones can be seen from the color and tentacles. Visual morphology, color fluctuations carpet anemone seen on day 1 to day 4, whereas stable symptoms on day 4 to day 10 . Carpet anemone averaged recovery or recovery of body condition anemones on the 14th day. 
This indicates that there have been a fragmentation wound healing results. The process of wound healing carpet anemone average on the 11th day until the wound closure process to-14 starting from the outer edges and then docked into so that the wound will be closed. On the ninth day of anemones begin to change color from pale brown in color fresh brown. On day 11 individual are their growing bulge on the former mucus and phlegm is not present in the cutout section. In this treatment anemones cut on the fifth day moving flat on waring maintenance. The second treatment with three cuts on the first day already mucus. Similarly, treatment of all individuals clear slime in a former carpet anemone fragment. Results of research on the soft coral reef that after the cut to fragment, it will issue a soft coral mucus as a natural response to repair the damaged tissue to close the wound (Romansyah, 2011).

The third treatment or cutting four times during the first observation, some individuals have not made a response to the fragmentation that is done because the surface of the cutting body is still white and no mucus. At the time of the transplanted corals will change color and mucus. This indicates that the soft coral stress. Soft coral adaptation period is the most critical because of the soft corals have to adjust to the environment. Soft corals will secrete mucus (phlegm) in the long term if the water is less supportive conditions for life. Mucus serves as a self-protection from the outside environment and will return to normal if it has stabilized (Zulfikar, 2003). This makes the treatment of four carpet anemone body parts into a whole separate so that makes five new individuals after fragmentation is performed. In this treatment as well as all treatments that exist with cutting responds with mucus and reintegration or recovery progresses slowly every new individual anemones carpet.

Clark and Maldive (1995) in Nani (2003) states that the survival rate of coral living soft levels are a coral there is softw that shows that still survive and stay active Operating physics and biology during specific time periods. Depending on the level continuity of life precision treatment method is especially hearts fragment, biological factors, such as physiological factors type soft coral the fragmented, and the response against enviroment. Fragmented condition life once cleavage has the highest success by $100 \%$, followed by treatment prayer that is $75 \%$, and treatment three ie $75 \%$. While most success low that fragmentated fourth That $25 \%$.

The high survival rate of anemones on of because treatment allegedly at least one cutting the only cleaved being prayer section, in addition to the environmental factors maintenance performed on floating net cages. It singer according with Sujangka statement (2014) that the anemones carpet had a survival rate better than anemone sand. Results cleavage anemone performed in a controlled bath carpet anemone shows the survival rate of $90 \%$ while $65 \%$ sand anemones. The rapid development of the first treatment allegedly anemone in no many expends energy to heal wounds review. It case also influenced by a reciprocal relationship from zooxanthellae symbionts. Results fragament on soft coral, that process occurred hearts mutually beneficial relationship between polyps and zooxanthellae where zooxanthellae produce oxygen and nutrients needed by polyps (Jipriandi et al, 2013).

The success rate of the lowest life in treatment F4 suspected as more and more fragmentation is done then survival decreases. It is caused by each piece on a carpet anemone will require a lot of energy to be utilized wound closure, get food, do movement and for growth. Continually diminishing energy use and impact on mortality. Fragment size largely determines the success of life, as related to the rate of regeneration. According Harriott and Fisk (1988) in Zulfikar (2003), said to be successful if the number of soft corals that live on the whole is greater than 50 .

The treatment lowest survival rate of four suspected as more and more fragmentation is done then survival decreases. This is caused by the amount of cleavage on the carpet anemone will create stress levels vary so as to affect survival in Stichodactyla gigantea. Zulfikar (2003) explains that in order to reduce or eliminate stress, coral animals will make adjustments behavior. If not successful then life will go back to stress and even the stress it will grow and will have an impact on mortality. This is supported by Bak and Criens (1981) in Prastiwi (2011), that survival decreased in the treatment of suspected F4 for a response from the coral that has been cut so stressed and unable to sustain life. Fragment size largely determines the success of life, because it deals with the rate of regeneration and the ability to break away from the cover sediments. Harriott and Fisk (1988) in Zulfikar (2003), the transplant can be said to be successful if the amount of living coral transplanted whole is greater than 50\%. From the results of fragmentation which is divided into five parts that are no longer intact, it turns out the body parts of the anemone to survive, but do not get normal food supply (through the mouth). Of the number of individuals who die, most of which exceeds the number of deductions fragment one and two body parts anemone. Individuals with many pieces and the size become small experience greater stress than other treatments so as to survive in these conditions will be tough, while for the treatment or fragmentation second and three just a little death. 
Mannuputty (1998) in Subhan et al, (2012) found a decrease in survival due to the soft coral reefs are stressed failed to adapt. In these conditions coral microsymbiont, namely zooxanthellae will come out of the coral polyp tissue from not being able to photosynthesize in dark conditions. The release of zooxanthellae from the coral body can be seen from the color of pale coral color loss (Rani, 1999, in Subhan et al, 2012). Coral death process can be detected by a change in the color of coral, yatu from pale brown to white (Suharsono 1984 in Subhan et al, 2012). According to Rani (1999) in Prastiwi (2011), the coral to lose color due to the release of zooxanthellae from the coral polyp tissue, in response to the stress on coral polyps due to changes in the environment. The fragments can not adapt to the new environment and is also affected by the injuries found on the body of the soft corals after the removal of the previous environment.

Okubo (2004), factors that affect the survival of the transplanted coral or fragmented, there are three types of cuts that regard coral that will be transplanted, the size of the pieces of fragment The transplanted, and the cutting season. Based on research conducted Okubo (2004) that the size of the small cut vertically more likely to survive than on the cut horizontally.

\section{References:-}

1. Effendi, M.I. 1979. Fisheries Biology Methods. Gramedia Pustaka Utama. Jakarta.

2. Gusrina. 2008. Fish Culture Volume I. Directorate of Technical and Vocational Education. Jakarta

3. Indriany, M. 2005. Diatoms and Dinoflagellates Community Structure in Several Regions Aquaculture in the Saleh Hurun, Lampung. [Thesis] was not Made Public. Biological Studies Program. The state University of Jakarta. Jakarta.

4. Jipriandi, Pratomo, A., Irawan, H. 2013. Growth in Coral Acropora formosa with the Transplant Technique Different fragment sizes. Marine Studies Program Faculty of Marine Sciences and Fisheries Maritime University Raja Ali Haji Tanjungpinang. Riau. 10 p.

5. Murdiati T., B. 1997. Use of Antibiotics in Livestock enterprises. Veterinary Research Institute. Bogor.

6. Nani, 2003. Levels Survival and Growth Rate foliosa Montipora coral, Seriatopora hystrix, Millepora tenella and Heliopora coeruleal. [Thesis] was not Published. Study Program Marine Science and Technology. Faculty of Fisheries and Marine Science. Bogor Agricultural Institute. Bogor.

7. Noviani. 2006. Required Planaria growth with Artificial Regeneration Unggaran In Malay Sumiray River. [Thesis]. Faculty of Mathematics and Natural Sciences, State University of Semarang. Semarang.

8. Okubo N, H. Taniguchi, \& T. Motokawa. 2005. Successful Methods for Transplanting Fragment of Acropora formosa and Acropora hyacinthus. Coral Reef. Indonesian Institute of Sciences. Jakarta. 24: 333-342.

9. Prastiwi, D., I. 2011. Soft Coral Growth Lobophytum strictum Transplantation Results on Recirculation Systems with Different Light Conditions. [Thesis] was not Published. Study Program Marine Science and Technology. Faculty of Fisheries and Marine Science. Bogor Agricultural Institute. Bogor.

10. Purwati, P. 2002. Through Teripang population recovery Fission, Could? Oseana 27: 19-25.

11. Purwati, P dan Dwiono, S.A.P., Indiana, L.F., 2009. Shifting the Natural Fission of Holothuria atra (Aspidochirotida, Holothuroidea, Echinodermata). SPC Beche-demeer inform. Bull. 29 : 16-19.

12. Rifa'i, M. A. 2012. The Genetic Diversity of Symbiotic Algae in the Sea Anemone Stichodactyla Zooxanthellae gigantean (Forsskal 1775) Results on Asexual Reproduction. Bioteknologi 9 (2): 49-56.

13. Rifa'i, M. A. 2013. Mitotic index symbiont algae zooxanthellae in gigantean Stichodactyla Sea Anemone Asexual reproduction results. Marine Science. Maret 2013 Vol. 18(1): 7-13.

14. Rifa'i, M. A. and Jusoff Kamaruzaman, 2013. Mitotic Index of Algae Symbion Zooxanthellae from Sea Anemon from Asexual Reproduction.World Applied Sciences Journal 26 (Natural Resources Research and Development in Sulawesi Indonesia): 112-118.

15. Romansyah, Y. 2011. Antioxidant Content of Bioactive Compound Soft Coral Sarcophyton sp. Natural and Transplantation in the waters Ulau Scout, Seribu Islands. [Thesis] was not published. Study Program Marine Science and Technology. Faculty of Fisheries and Marine Science. Bogor Agricultural Institute. Bogor.

16. Subhan, B., Soedaharma, D., Arafat, D.,, Addupa, H., Rahmawati, F. 2012. Effect of Light on Survival and Growth Rate Soft Coral Lobophytum strictum (Octocoralia: Alcyonacea) Transplantation Results in the System. Journal of Fisheries and Marine Technology.3 (1): 35-42.

17. Sujangka, A. 2014. Breeding Anemone In Vegetative with fragmentation as an Alternative Method of Ornamental Fish Enterprises. Hall Marine Fisheries Lombok. Lombok.

18. Uji A.M. 2014. Benefit from Marine Animals and Plants. Indonesian Education Partners. Bandung. 
19. Ulfa, M. 2009. Influence of Different Types Of Lighting To Mitotic Index, Density and Morphology Zooxanthellae Anemones (Heteractis shame) on the Scale Laboratorium.[Thesis]. Studiy Program and Marine Technology Faculty of Fisheries and Marine Science, Bogor Agricultural University. Bogor.

20. Zulfikar. 2003. The growth and survival of coral (Caulastrea furcata and Cynarina lacrimaris) artificial fragmentation results in controlled conditions. [Thesis] was not published. Graduate program. Bogor Agricultural Institute. Bogor. 